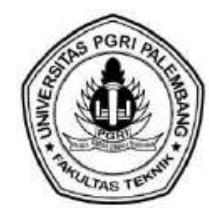

\title{
ANALISIS PENAMBAHAN LIMBAH LAS KARBIT SEBAGAI FILLER CAMPURAN ASPAL AC WC
}

\author{
Muhammad Iqbal $^{1 *}$, Amiwarti $^{2}$, Agus Setiobudi $^{3}$ \\ ${ }^{123}$ Prodi Teknik Sipil Fakultas Teknik Universitas PGRI Palembang \\ Jalan Jend A. YaniLr. Gotong Royong 9/10 Ulu Palembang Sumatera Selatan \\ *Corresponding Author, Email: Iqbalmuhammad34951 @gmail.com
}

\begin{abstract}
ABSTRAK
Pengaruh terhadap penambahan limbah las karbit sebagai filler. Penelitian ini betujuan untuk mengetahui hasil dari pengujian pengaruh limbah las karbit sebagai filler pada lapisan aspal AC WC dengan menggunakan uji karakteristik Marshall Test.Dalam penelitian ini menggunakan metode kuantitatif yang mana datanya diambil data dan hasil dari pengujiannya dari laboraturium AMP PT. Hakaaston palembang. Hasil penelitian dari pengaruh kuat tekan Marshall Test dengan penambahan limbah las karbit sebagai filler pada campuran asphalt concrete wearing course (AC-WC) dengan variasi $1 \% 2 \% 3 \%$ mengalami kenaikan serta mengalami penurunan terhadap pengujian Marshall Test. Dan pada penelitian tersebut dapat disimpulkan bahwa untuk penambahan limbah las karbit sebagai filler pada campuran asphalt concrete wearing course (AC-WC) dengan variasi $1 \% 2 \% 3 \%$ untuk nilai karakteristik tidak bisa digunakan dalam pengganti filler abu batu.
\end{abstract}

Kata kunci : Limbah, Las Karbit, Filler

\section{PENDAHULUAN}

Perencanaan geometrik jalan yaitu suatu perencanaan kontruksi jalan, yang meliputi pola dalam rancangan arah dan dimensi visualisasi nyata dalam suatu trase jalan beserta bagianya, persyaratan parameter disesuaikan dengan adanya kendaraan seta adanya lalu lintas. Dan perencanaan geometrik jalan untuk dapat disuahakan menciptakan hubungan yang serasi antara faktor-faktor yang berkaitan dengan parameter tersebut diatas, sehingga akan dihasilkan suatu efisiensi keamanan serta kenyamanan yang paling optimal, dalam batas-batas pertimbangan toleransi yang masih dianggap layak. Pada Perencanaan geometrik secara umum menyangkut aspek-aspek perencanaan elemen jalan seperti lebar jalan, tikungan, kelandaian jalan dan jarak pandangan serta kombinasi dari bagian-bagian tersebut, baik untuk suatu ruas jalan maupun untuk perlintasan diantara dua atau lebih ruas jalan.

Perencanaan geometrik akan lebih dahuluu memperhatikan beberapa parameter yang langsung terkait dengan karakteristik turunannya dan lalulintas. berbeda kaitan terhadap perencanaan struktur jalan yang utamanya lebih menyoroti factor kekuatan akibat beban dari lalu lintas tersebut. Dalam perencanaannya bentuk dan pola geometrik sedemikian rupa harus direncanakan sehingga jalan yang bersangkutan dapat memberikan kenyamanan serta pelayanan yang optimal kepada lalu lintas sesuai dengan fungsinnya.

\section{TINJAUAN PUSTAKA}

Tanah saja biasanya tidak cukup kuat dan tahan, tanpa adanya defomasi yang berarti, terhadap beban roda berulang. Untuk itu perlu lapis tambahan yang terletak antara tanah dan roda atau lapis paling atas dari bahan jalan. Lapis tambahan ini dapat dibuat dari 
bahan khusus yang terpilih (yang lebih baik), yang selanjutnya disebut lapis keras / perkerasan / pavement. (suprapto : $2005: 1$ )

Mengingat volume perkerjaan jalan, pada umumnya diinginkan perkerasan yang murah, namun masih dapat memenuhi tuntunan lalulintas nya. Pada mulanya kontruksi perkerasan dikelompokkan menjadi tiga bagian yaitu perkerasan lentur (flexible) dan perkerasan kaku (rigid), selanjutnya menunjukkan perkembangan bahwa adanya berbagai bentuk perkerasan lainnya.

\section{Lapisan Perkerasan Jalan}

Menurut (Suprapto 2004) pada mulanya kontruksi perkerasan di kelompokan menjadi perkerasan lentur (flexible) dan perkerasan kaku (rigid)

\section{Perkerasan Lentur (flexible pavament)}

Bahan kontruksi perkerasan lentur menggunakan bahan bahan ikat( aspal, tanah liat) dan batu, perkerasaan ini umunya terdiri-dari 3 lapisan atau lebih yaitu: lapisan permukaan, lapisan pondasi bawah, dan yang terletak di atas tanah

\section{Lapisan Perkerasan Kaku}

Perkerasan kaku umumnya terdiri dari atas dua lapis yaitu lapisan pondasi atas dan lapisan pondasi bawah. Dimana lapisan pondasi atas dan lapisan pondasi bawah memberikan sumbangan yang bersar terhadap daya dukung perkerasan terutama didapat dari plat beton. Hal tersebut disebabkan oleh sifat beton yang cukup kaku sehingga dapat menyebarkan beban pada bidang yang luas dan menghasilkan tegangan yang rendah pada lapisan-lapisan dibawahnya

\section{Material perkerasan Jalan}

Agregat adalah suatu partikel yang berwujud butiran-butiran yang penggunaannya merupakan salah satu dari kombinasi dengan berbagai macam tipe yaitu mulai dari material di semen sebagai bahan untuk membuat beton, pada lapisan pondasi jalan. Agregat diartikan secara umum sebagai formasi kulit bumi yang padat dan keras. ASTM mengartikan agregat yaitu sebagai bahan yang terdiri dari mineral padat, berupa massa berukuran besar ataupun berupa fragmen-fragmen. Agregat merupakan komponen utama dari struktur perkerasan jalan, yaitu 90-95\% agregat berdasarkan persentase berat atau 75$85 \%$ agregat berdasarkan persentase volume. Dengan demikian kualitas perkerasan jalan ditentukan dari hasil campuran material lainnya dengan campuran sifat agregat dan hasil campuran agregat (Tenriajeng : $2002: 27$ )

Material untuk perkerasan jalan meliputi:

1. Batu pecah

2. Batu belah

3. Batu kali

Bahan ikat yang di pakai:

1. Aspal

2. Semen

3. Tanah liat 


\section{METODE PENELITIAN}

Dalam penelitian ini untuk rancangan campuran aspalnya sendiri menggunakan metode Marshall Test. Adapun Langkah-langkah rancangan dalam metode ini yaitu untuk : mempelajari gradasi spesifikasi agregat campuran yang diinginkan spesifikasi umum dari dinas PU bina marga bidang jembatan dan bidang jalan revisi 2 tahun 2010. Dimana perancangan proporsi agregat dipilih dari gradasi yang sesuai Bina Marga tahun 2010 . untuk prinsip kerja metode analitis ini yaitu menentukan gradasi agregat yang telah dipilih kemudian menghitung butiran tertahan dan butiran yang lolos sesuai spesifikasi yang sehingga dimana bisa didapatkannya komposisi agregat halus , agregat kasar dan filler.

Penelitian ini dilakukan di laboratorim PT, Hakaaston KUP(Kepala Unit Pelaksana) Jenis penelitian ini adalah penelitian eksperimen di laboratorium berupa pengujian aspal dengan bahan limbah las karbit.

\section{Teknik Pengumpulan Data}

Adapun metode penelitian yang digunakan penulis adalah sebagai berikut :

1. Pengumpulan Data Sekunder

Data sekunder dilakukan dengan cara mencari data dan mencari bahan dari jurnal atau buku yang berkaitan dengan pemanfaatan limbah kertas. Kemudian browsing internet sebagai masukan-masukan guna menyelesaikan laporan ini.

2. Pengumpulan Data Primer

Pengumpula data primer dengan cara melkukan/ observasi dan penelitian secara langsung di labolaturium guna mendapatkan data-data yang diperlukan secara lengkap.

Pada penelitian ini sempel dibuat sebanyak 6 benda uji dengan/menggunakan variasi campuran $1 \%, 2 \%$ dan 3\%. Masing-masing variasi campuran dibuat 2 sempel.

Pelaksanaan penelitian dilakukan di Laboratorium PT.Hakaaston Bahan Palembang yang beralamat di jalan Mayjen Yusuf Singedekane Musi/2 Palembang dan tahapan penelitian sebagai berikut :

a. Peralatan Penelitian

Semua peralatan yang dibutuhkan untuk penelitian ini tersedia di laboraturium, peralatan yang digunakan adalah :

a) Saringan / ayakan saringan digunakan untuk campuran aspal AC-WC

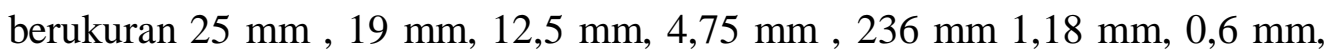
$0,3 \mathrm{~mm}, 0,15 \mathrm{~mm}, 0,075 \mathrm{~mm}$ dan pan.

b) Timbangan yang akan digunakan dalam penelitian ini antara lain

- Timbangan kapasitas $20 \mathrm{~kg}$ dengan ketelitioan 1 gram , untuk agregat kasar.

- Timbangan digital kapasitas 2 kg ketelitian 2 gram, untuk agregat halus dan filler.

c) Gelas ukur.

d) Tabung silinder.

e) Kertas hisap (karton).

f) Batang penumbuk berdiameter $16 \mathrm{~mm}$ dan panjang $610 \mathrm{~mm}$.

g) Mistar.

h) Cetakan benda uji (mold). 
i) Talam atau pan.

j) Oven.

k) Piknometer.

1) Mesin uji marshall.

m) Mesin uji los angeles.

n) Satu set alat dongkrak.

o) Ember

p) 16. Kuas .

q) 17. Palu karet.

r) 18. Jangka sorong.

s) 19. Thermometer

t) 20. Kompor

u) 21. Bak perendam

v) 22. kuali

b. Bahan Penelitian

Bahan-bahan yang digunakan dalam penelitian ini meliputi material penyusun untuk komposisi campuran aspal AC WC yang ditambahkan limbah las karbit sebagai filler sebagai bahan tambahannya, dimana :

a) Agregat kasar (split) agregat kasar yang digunakan pada penelitian ini yaitu agregat alami yang dipecahkan dengan ukuran 1/2 dan 1/1 dimana material berasal dari ciwandan merak Banten yang disediakan oleh PT. Diaz.

b) Agregat halus agregat yang digunakan pada penelitian ini berupa abu bata yang berasal dariCiwandan Merak Banten yang disediakan oleh PT. Diaz

c) Filler penelitian ini berupa bakaran abu ampas tebu sebagai filler. Pada campuran aspal sebagai bahan utama filler.

d) Aspal curah (bitumen) yang digunakan adalah aspal penetrasi 60/70 yang berada di laboraturium PT. Haaston KUP (kepala unit pelaksana) palembang. Dalam hal ini aspal curah yang dipakai adalah merk shell 60/70 dari singapura yang dipasok oleh perusahaan PT. Rabana aspalindo.

\section{HASIL DAN PEMBAHASAN}

Hasil penelitian campuran Marshall Test AC WC normal untuk menentukan kadar aspal optimum (KAO) dengan variasi kadar aspal bisa dilihat di tabel sebagai berikut :

Tabel 1. Hasil olah data pemeriksaan marshall test AC WC Normal

\begin{tabular}{|r|c|c|c|r|r|r|r|}
\hline No & AC WC & \multirow{2}{*}{ Satuan } & \multirow{2}{*}{ Spesifikasi } & \multicolumn{4}{|c|}{ Kadar Aspal Optimum (0\%) } \\
\cline { 5 - 8 } & Normal & & & 5,0 & 5,0 & 5,0 & \multicolumn{1}{c|}{5,0} \\
\hline 1 & Density & Gr/cm & - & 2,274 & 2,276 & 2,246 & 2,284 \\
\hline 2 & VMA & $\%$ & Min 15 & 14,94 & 15,33 & 16,92 & 15,48 \\
\hline 3 & VFB & $\%$ & Min 65 & 63,54 & 69,29 & 73,14 & 74,60 \\
\hline 4 & VIM & $\%$ & $3,0-5,0$ & 5,45 & 4,71 & 4,54 & 3,93 \\
\hline 5 & Stabillity & $\mathrm{Kg}$ & Min 1200 & 1141,1 & 1267,0 & 1196,0 & 1181,9 \\
\hline 6 & Flow & $\mathrm{Mm}$ & $2,0-4,0$ & 3,35 & 3,45 & 3,70 & 3,60 \\
\hline 7 & $\mathrm{MQ}$ & $\mathrm{Kg} / \mathrm{Cm}$ & Min 250 & 341,6 & 367,5 & 324,7 & 328,3 \\
\hline
\end{tabular}

Sumber : Hasil pengolahan data dari laboratorium PT. Hakaaston Palembang 
Hasil pengujian campuran aspal AC WC normal dalam penentuan kadar aspal normal ( KAO) di dapatkan bahwa pencampuran aspal yang sesuai speksifikasi dengan kadar aspal 5,7\% dimana pengujian marshall sebagai berikut :

a) Nilai Density di dapat sebesar 2,246 gr/cc.

b) Nilai VMA(void in Marshall Anggregat) sebesar 16,92\%.

c) Nilai VFB (Void Filled Bitumen) sebesar 73,14\%.

d) Nilai VIM (Void in Mix) sebesar 4,54\%.

e) Nilai stabilitas marshall sebesar $1169,0 \mathrm{~kg}$.

f) Nilai flow (kelelahan) sebesar $3,70 \mathrm{~mm}$.

g) Nilai Marshall Quotient sebesar 324,7 kg/mm.

Perbandingan Nilai-Nilai Marshal test Campuran Aspal AC WC Normal dan Variasi Penambahan Filler limbah las karbit secara keseluruhan :

\begin{tabular}{|c|c|c|c|c|c|c|}
\hline $\begin{array}{c}\text { Kadar } \\
\text { Filler }\end{array}$ & $\begin{array}{c}\text { Stabilitas } \\
(\mathbf{K g})\end{array}$ & $\begin{array}{c}\text { VIM } \\
(\boldsymbol{\%})\end{array}$ & $\begin{array}{c}\text { VFB } \\
(\boldsymbol{\%})\end{array}$ & $\begin{array}{c}\text { VMA } \\
(\boldsymbol{\%})\end{array}$ & $\begin{array}{c}\text { FLOW } \\
(\mathbf{m m})\end{array}$ & $\begin{array}{c}\text { MQ } \\
(\mathbf{K g} / \mathbf{m m})\end{array}$ \\
\hline $0 \%$ & 1196,0 & 4,54 & 73,14 & 16,92 & 3,70 & 324,69 \\
\hline $1 \%$ & 1019,2 & 17,1 & 38,62 & 27,84 & 10,2 & 200,78 \\
\hline $2 \%$ & 998,4 & 12,3 & 50,80 & 23,62 & 5,95 & 168,08 \\
\hline $3 \%$ & 1331,2 & 9,9 & 54,03 & 21,60 & 5,65 & 238,95 \\
\hline Spek & Min 1200 & $\mathbf{3 , 0 - 5 , 0}$ & Min 65 & Min 15 & $\mathbf{2 , 0 - 4 , 0}$ & Min 250 \\
\hline
\end{tabular}

\section{KESIMPULAN}

Berdasarkan hasil penelitian maka hasil penelitian dapat di simpulkan secara keseluruhan bahwa pengaruh kuat tekan marshall test dengan menggunakan ampas tebu sebagai campuran aspal AC WC variasi penambahan filler 1\%,2\% dan 3\% semuanya tidak masuk spesifikasi Umum 2010 Revisi 2 Dinas PU Bina Marga namun ada satu variasi yang lebih mendekati spesifikasi yaitu pada variasi campuran $3 \%$.

\section{DAFTAR PUSTAKA}

Andi Tenrisukki Tenriajeng 2002, Rekayasa Jalan Raya , Gunadarma, Jakarta, Indonesia. Hamirhan Saodang, 2010, Kontruksi Jalan Raya, Penerbit NOVA Bandung, Indonesia.

Silvia Sukirman 1999, Dasar-dasar perencanaan Geometric Jalan, penerbit NOVA Bandung, Indonesia.

Silvia Sukirman 1999, Perkerasan Lentur Jalan Raya, penerbit NOVA, Bandung, Indonesia.

Suprapto TM, 2003, Bahan Dan Struktur Jalan Raya, penerbit KMTS FT UGM, Indonesia. 